\title{
¿Qué líder quiero ser?
}

\section{What leader do I want to be?}

\author{
Arlen Cerón Islas ${ }^{a}$, Diana Soledad Guzmán Pérez ${ }^{b}$, Nicolás Cruz Martínez ${ }^{c}$
}

\begin{abstract}
:
Leadership models in a certain way become models of leader participation; in these degrees of participation it is seen, the weight of the boss is decreasing as the group's weight increases as such. This undoubtedly has a close connection with the humility of the leader and with the capacity of the group's members.
\end{abstract}

To be a leader you need:

1. Have an adequate strategic planning that allows the fulfillment of the mission and vision, observing values

2. Develop skills that identify the strengths and opportunities to become a humble leader capable of learning

3. Guide employees with trust, respect, equality and fair treatment.

4. Evaluate performance with the purpose of being able to emit an objective opinion.

5. Observe habits that allow the participation of the members.

\section{Keywords:}

Leader, planning, values

\section{Resumen:}

Los modelos de liderazgo pasan en cierto modo a convertirse en modelos de la participación del líder; en estos grados de participación se ve, el peso del jefe va disminuyendo a medida que aumenta el del grupo como tal. Ello tiene indudablemente estrecho nexo con la humildad del líder y, con la capacidad de los componentes del grupo.

Para ser un líder es necesario:

1. Tener una adecuada planeación estratégica que permitan el cumplimiento de la misión y visión, observando valores.

2. Desarrollar habilidades que permita identificar las fortalezas y oportunidades para convertir en un líder humilde capaz de aprender.

3. Guiar a los colaboradores con confianza, respeto, igualdad y trato justo.

4. Realizar una evaluación del desempeño con la finalidad de poder emitir una opinión objetiva.

5. Observar hábitos sanos que permitan la participación de los integrantes.

\section{Palabras Clave:}

Líder, planeación, valores

\section{Mapa conceptual}

\footnotetext{
${ }^{a}$ Autor de Correspondencia, Universidad Autónoma del Estado de Hidalgo, Instituto de Ciencias Económico Administrativas, ORCID: 00000003-3982-5053,Email: arlenc@uaeh.edu.mx

b Universidad Autónoma del Estado de Hidalgo, Instituto de Ciencias Económico Administrativas, Email: dianasolmx@gmail.com

c Universidad Autónoma del Estado de Hidalgo, Instituto de Ciencias Económico Administrativas, Email: mc.melanicruz@gmail.com
} 


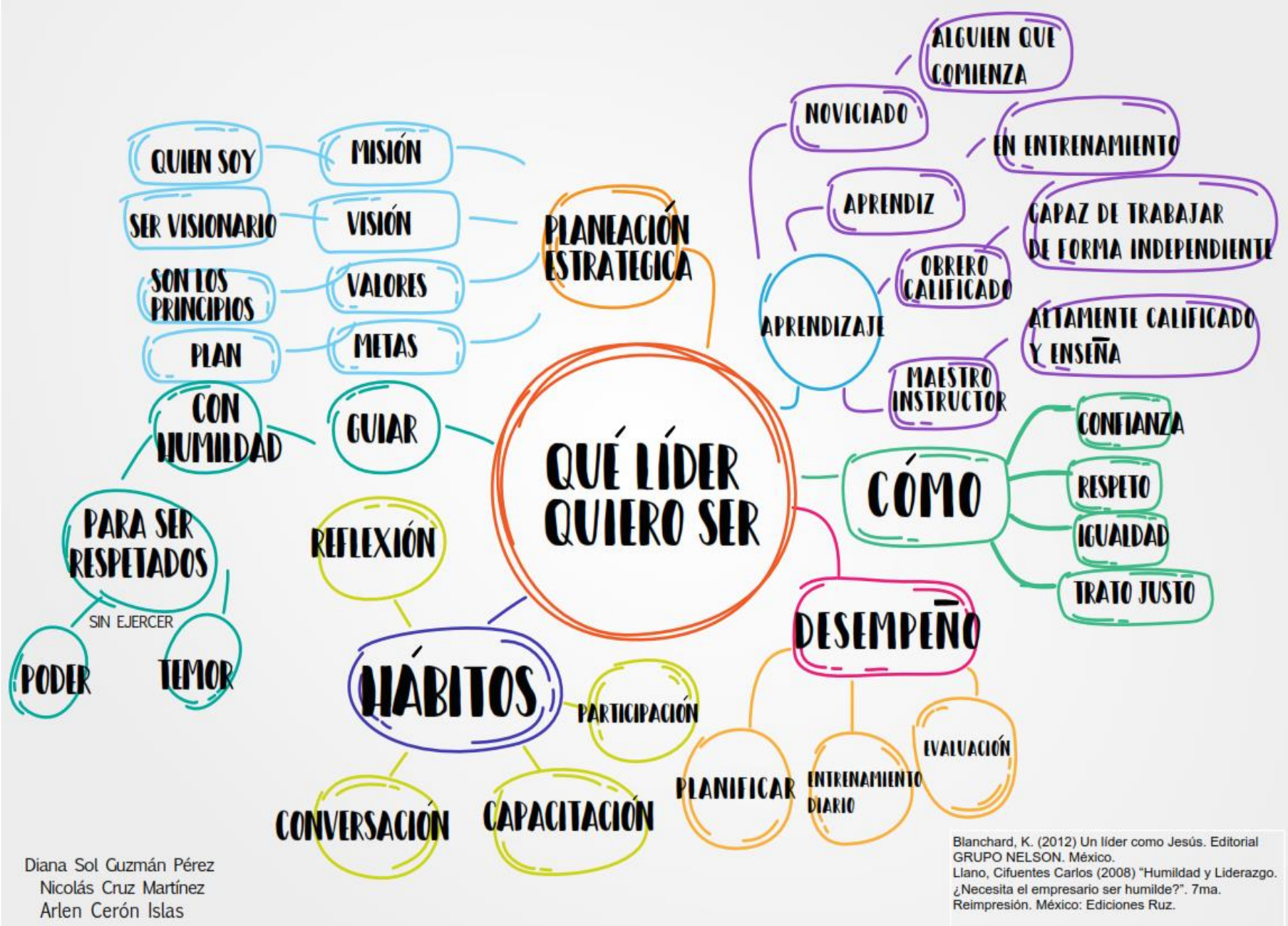

\section{Referencias}

[1] Blanchard, K. Un líder como Jesús. México. Editorial Grupo Nelson.; 2012.

[2] Llano, Cifuentes Carlos () “Humildad y Liderazgo. ¿Necesita el empresario ser humilde?”. 7ma. Reimpresión, Ediciones Ruz, México; 2008. 